\title{
Proactive social validation of methods and procedures used for training speech production in aphasia
}

\author{
Tyson G. Harmon \\ Brigham Young University, tyson_harmon@byu.edu \\ Lucy Hardy \\ University of North Carolina at Chapel Hill \\ Katarina L. Haley \\ University of North Carolina at Chapel Hill
}

Follow this and additional works at: https://scholarsarchive.byu.edu/facpub

Part of the Communication Sciences and Disorders Commons

\section{Original Publication Citation}

Harmon, T. G., Hardy, L., Haley, K. L. (2018). Proactive social validation of methods and procedures used for training speech production in aphasia. Aphasiology, 32(8):922-943.

\section{BYU ScholarsArchive Citation}

Harmon, Tyson G.; Hardy, Lucy; and Haley, Katarina L., "Proactive social validation of methods and procedures used for training speech production in aphasia" (2018). Faculty Publications. 4169. https://scholarsarchive.byu.edu/facpub/4169 


\title{
Proactive social validation of methods and procedures used for training speech production in aphasia
}

\author{
Tyson G. Harmon \\ Lucy Hardy \\ Katarina L. Haley
}

Division of Speech and Hearing Sciences, Department of Allied Health sciences, University of North Carolina, Chapel Hill, NC

Tyson G. Harmon

Division of Speech and Hearing Sciences

321 S. Columbia St

UNC-CH Bondurant Hall CB\#7190

Chapel Hill NC 27599

Email: Tyson_Harmon@med.unc.edu

Telephone: 919-500-6233

Lucy Hardy

Division of Speech and Hearing Sciences

$321 \mathrm{~S}$. Columbia $\mathrm{St}$

UNC-CH Bondurant Hall CB\#7190

Chapel Hill NC 27599

Email: lucyebrimhall@gmail.com

Please address correspondence to:

Katarina L. Haley

Division of Speech and Hearing Sciences

3124 Bondurant Hall

University of North Carolina at Chapel Hill

Chapel Hill, NC 27599-7190

Email: Katarina_Haley@med.unc.edu

Telephone: 919-445-0341

Fax: 919-966-0100

Word Count: 7,492

Disclosure of Interest: The authors report no conflicts of interest. 


\begin{abstract}
Background: Social validation evaluates the importance and acceptability of treatment goals, procedures, and outcomes. Previous studies for treatments that train speech production in aphasia have applied social validation during the post-treatment period or to treatment protocols that are already fully developed.

Aims: The purposes of this study were to (1) examine the social validity of goals and procedures experienced in speech production treatment for people with aphasia and (2) evaluate the feasibility of procedural choice-making during such tasks.

Method: Seven people with aphasia and eight speech-language pathologists were interviewed about previous treatment that targeted speech production. Participants were also observed and/or provided feedback following a simulated practice experience or description of practice techniques that were part of a treatment approach under development. Detailed field notes were obtained and analyzed.

Results: Qualitative analysis revealed four themes: (1) experience with treatment, (2) experience with practice, (3) therapeutic engagement, and (4) procedural choice-making. The first three themes related to previous experiences with speech production treatment and the fourth pertained to comments and observations regarding the simulated practice experience.

Conclusions: The variety of approaches, strategies, and cueing options that participants reported combined with comments regarding therapeutic engagement and the simulated practice indicated that people with aphasia and speech-language pathologists value control, choice, and flexibility when training speech production. Integrating procedural choice-making with speech production practice is feasible and has the potential to increase motivation and improve implementation.
\end{abstract}




\section{Introduction}

Many persons with aphasia (PWAs) experience difficulties with the production of speech sounds. These difficulties can result from impaired phonological retrieval or encoding (i.e., aphasia with phonemic paraphasia [APP]), impaired motor programming (i.e., apraxia of speech [AOS]), or a combination of phonological and motor impairment. Many different intervention approaches have been developed to treat speech production problems in aphasia. Treatments for AOS have primarily targeted either articulation or prosody and treatments for phonemic paraphasia have focused on improving sentence repetition and self-monitoring (Ballard et al., 2015; Franklin, Buerk, \& Howard, 2002; Kohn, Smith, \& Arsenault, 1990; Wambaugh, Duffy, McNeil, Robin, \& Rogers, 2006). Regardless of the specific impairment or treatment approach, success likely depends on the client's drive to follow through with treatment programs (i.e., personal motivation) and best practices being taken up successfully in the clinic (i.e., implementation science). While motivation and implementation research has only recently been applied to aphasiology (Biel, Nitta, \& Jackson, 2018; Douglas, Campbell, \& Hinckley, 2015), social validation methods have been available for almost 40 years. These methods can help in the development of treatments that are both motivating to PWAs and implemented by speechlanguage pathologists (SLPs).

Motivation and implementation in speech production training for aphasia is of particular interest because of the importance of frequent practice. The majority of intervention studies for AOS require participants to practice at least three times a week (e.g., Wambaugh \& Martinez, 2000; Wambaugh, Nessler, Cameron, \& Mauszycki, 2012; Wambaugh, Wright, \& Nessler, 2012) with many requiring practice four or more days a week from fifteen minutes up to two hours each day (see e.g., Kendall, Rodriguez, Rosenbek, Conway, \& Gonzalez-Rothi, 2006). 
Although what is practiced and how it is practiced influence treatment success, several studies suggest that the total time spent practicing is key to achieving positive outcomes (e.g.., Bhogal, Teasell, Foley, \& Speechley, 2003; Cherney, 2012). To date, the optimal dose, frequency, and total intervention duration remain to be determined and the effects of intervention type, stimuli, participant characteristics, and environmental factors are still unclear (Ballard et al., 2015; Cherney, 2012). Incorporating principles known to strengthen motivation and improve implementation is likely beneficial to adequate practice and can be accomplished through proactive social validation.

\section{Social Validation, Motivation, and Implementation}

Social validation is a means of evaluating the importance and acceptability of treatments to stakeholders at three levels: (1) goals, (2) procedures, and (3) effects (Wolf, 1978).

Stakeholders have been identified as direct consumers (i.e., those who receive the intervention), indirect consumers (i.e., those who purchase, hire, or administer the intervention), immediate community (those who regularly interact with consumers), and extended community (those who do not regularly interact with consumers but live in the same community; Schwartz \& Baer, 1991). In the present study we are concerned with proactively investigating the importance and acceptability of speech production treatments for the direct consumer (i.e., PWAs) and one group of indirect consumer (i.e., SLPs). In contrast to the more commonly implemented retrospective approach to social validation, which occurs after consumers have undergone treatment, we take a proactive approach by evaluating the relevance and acceptability of methods and procedures prior to incorporating them into a later treatment study. Our rationale is that incorporating desirable features will improve treatment feasibility and impact. In addition, we hypothesized that the social validation itself would support motivation and improve implementation. 
Several theories of motivation emphasize the importance of autonomy and competence in driving people to exert effort toward accomplishing a goal (Bandura, 1997; Deci \& Ryan, 1987; Locke \& Latham, 2002). Autonomy is characterized by a full and complete endorsement of the behavior in which one is engaged and competence is the feeling that one is capable of successfully performing a task or participating in an activity (Deci \& Ryan, 2012; Ryan \& Deci, 2000). One practical strategy for supporting competence and autonomy in any treatment application is to ask for, and integrate, input from those who will receive the treatment. Collaborative planning is an integral part of client-centered practice, but can also be conceptualized as a form of social validation. In the broader educational and behavioral intervention literature, proactive evaluation of social validity has been used to modify goals and procedures according to consumer preferences (Schwartz \& Baer, 1991; Wolf, 1978).

Seeking consumer feedback about treatments has also been proposed as one solution for bridging the research-practice gap (Douglas et al., 2015). Implementation science seeks to bridge this gap through systematic investigation of the barriers and solutions associated with applying research findings to practice. Many theories highlight critical constructs for successful implementation in healthcare settings (e.g., Mendel, Meredith, Schoenbaum, Sherbourne, \& Wells, 2008; Rycroft-Malone, 2004). Overlapping constructs have been shown to repeatedly emphasize the importance of consumer perceptions about the intervention (Damschroder et al., 2009). For example, after synthesizing 19 implementation theories, Damschroder et al., (2009) repeatedly emphasized that the value consumers place on the intervention and the choices they make about the intervention process influence how effectively it is implemented. Social validation provides a method for investigating consumers' perceptions about interventions during 
their development in order to make adjustments that will ultimately contribute to improved motivation and implementation.

\section{Three Levels of Social Validation}

The first level of social validation is whether the treatment goals are important to consumers and relevant to the changes they desire (Schwartz \& Baer, 1991; Wolf, 1978). Perceptions about treatment goals among PWAs is rarely the target of research (see Worrall et al., 2011 for one exception) and, to our knowledge, no study has examined their perceptions about goals related specifically to the training of speech production. While most speech treatments for aphasia rely on targets selected by SLPs, researchers are beginning to recognize the value of including PWAs in the selection process (e.g., Hersh, Worrall, Howe, Sherratt, and Davidson, 2012). Collaborative identification of treatment goals has been applied to script training, wherein PWAs and SLPs collaborate to determine what topics to target (Goldberg, Haley, \& Jacks, 2012; Holland, Halper, \& Cherney, 2010; G. L. Youmans, Youmans, \& Hancock, 2011), and Combined Aphasia and Apraxia of Speech Treatment (CAAST), wherein clinicians build targets from patients' elicited verbal responses to action pictures (Wambaugh, Wright, Nessler, \& Mauszycki, 2014). Based on motivational principles of autonomy and competence, understanding the treatment goals that PWAs self-endorse and targeting these goals in intervention should lead PWAs to pursue them with greater effort and persistence.

The second level of social validation is whether consumers deem the treatment techniques to be acceptable (Schwartz \& Baer, 1991; Wolf, 1978). Almost all speech production treatments are directed by an SLP who guides their client's speech production with the help of cues and models (e.g., Albert, Sparks, \& Helm, 1973; Kearns, 1985; Wambaugh, KalinyakFliszar, West, \& Doyle, 1998). Patients are often passive respondents who contribute little to 
treatment design and administration. Advancements in technology, however, have provided greater opportunity for client-driven treatment procedures such as computerized programs that expose PWAs to multiple cueing options (Doesborgh et al., 2004) and allow them to selfadminister therapy (Stark \& Warburton, 2016; Varley et al., 2016). One way to validate treatment procedures socially is to ask consumers how they like or liked the procedures. Another, more proactive approach, is to provide choices of techniques or strategies to use during intervention.

Social validation of effects determines whether consumers are satisfied with treatment outcomes (Schwartz \& Baer, 1991; Wolf, 1978). A handful of studies have retrospectively evaluated the social validity of the effects of speech production treatment; results from these studies, however, have been of limited use for program improvement. For example, immediate and extended community members rated PWAs as speaking with a slower rate, less effort, more naturalness, and relaying more intelligible information as the result of treatment (Brendel \& Ziegler, 2008; Kendall et al., 2006; S. R. Youmans, Youmans, \& Hancock, 2011). In addition, PWAs have been shown to perceive themselves as communicating more easily and naturally as well as feeling less anxious and more confident about speaking as the result of speech production treatment (Kendall et al., 2006; G. L. Youmans et al., 2011). While these findings are valuable, their retrospective nature limit their use for optimizing treatment methods.

There is inherent limitation in restricting subjective evaluation to the post-treatment period or to fully developed treatment protocols. If the point of social validation is not just to demonstrate acceptability, but also to improve the treatment procedures (Schwartz \& Baer, 1991), it should be examined systematically and proactively. In our laboratory, we are currently developing speech production treatment techniques that incorporate client choice-making during 
planning and practice. The choice-feature is, in itself, a form of case-by-case social validation (or in other terminology an autonomy-supportive strategy to enhance motivation). However, without input from the intended direct and indirect consumers, we have limited ability to predict how the treatment will be received. Can we realistically assume that PWAs and SLPs will be comfortable accepting and offering the choices we envisioned in the laboratory? Will they find other components of the treatment appealing? Would addition or modification of basic treatment components improve its acceptability? Rather than evaluating social validity after research participants received the fully developed intervention, we thought it more constructive to seek consumer input proactively. We thought qualitative input, in particular, would help us focus our research on techniques that are not only potentially active and effective, but also viewed as practical, interesting, and important by PWAs and the SLPs with whom they collaborate.

The purpose of the present study was to inform procedures for offering choices in goal setting and practice for PWAs during speech production training via a tablet computer based on input from both direct and indirect consumers. We pursued this purpose by (1) examining the social validity of goals and procedures previously experienced by PWAs and SLPs while receiving or administering speech production treatment and (2) evaluating feasibility and subjective experience of procedural choice-making during a simulated practice experience that incorporated features of the new client-driven treatment program we were developing.

\section{Method}

We used a qualitative descriptive research design with semi-structured interview being our form of data collection. The study was approved by the University of North Carolina at Chapel Hill Institutional Review Board.

\section{Participants}


Seven PWAs ( 3 male, 4 female; see Table 1) and eight SLPs (2 male, 6 female; see Table 2) participated in the study. The average age of participants with aphasia was 63 years (range = 45-80). All had acquired aphasia as the result of a stroke; the average time post-onset was 6 years and 8 months (range $=0 ; 3-16 ; 0$ ). Aphasia severity was classified based on the Aphasia Quotient from the Western Aphasia Battery-Revised (Kertesz, 2006). A motor speech evaluation (Haley, Jacks, de Riesthal, Abou-Khalil, \& Roth, 2012; Wertz, LaPointe, \& Rosenbek, 1984) was conducted to evaluate speech production severity and characterize the profile. Criteria for AOS included relatively long average syllable duration during word repetition and relatively high proportions of both substitution and distortion sound errors. APP was diagnosed based on a relatively high proportion of substitution errors, relatively few distortion errors, and relatively normal syllable duration in multisyllabic words. The severity of speech production difficulties was estimated as a motor speech evaluation accuracy score by calculating the percent of target words (from a total of 54) that were produced without phonemic errors.

[Table 1 near here]

Three participants (PWA1, PWA2, PWA3) had severe aphasia. On the Western Aphasia Battery Revised (WAB-R; Kertesz, 2006), PWA1 and PWA2 obtained an Aphasia Quotient (AQ) of 33.9 and 41.1, respectively, profiling with Broca's aphasia and AOS. The output for PWA3 was very limited and marked by numerous sound errors. Auditory comprehension was reduced for conversation outside the immediate context. Due to the severity of his difficulties, we did not complete a formal speech and language evaluation. Two participants (PWA4, PWA5) had moderate aphasia. PWA4 had an AQ of 53.2 and profiled with Broca's aphasia and AOS, whereas PWA5 had an AQ of 65.4 and profiled with Conduction aphasia and APP. Two 
participants (PWA6 and PWA7) profiled with mild anomic aphasia. PWA6 was diagnosed with APP and PWA7 was diagnosed with AOS.

SLPs were recruited through email invitations that were sent to colleagues who worked in rehabilitation settings. To participate in the study, SLPs had to report experience working on speech production in aphasia. Table 2 shows demographic information for SLPs who demonstrated a broad range of experience (i.e., 1 to 34 years) and worked mostly in outpatient rehabilitation although other work settings included inpatient rehabilitation, skilled nursing facility, and private practice.

[Table 2 near here]

\section{Procedures}

Data Collection. Data were collected through semi-structured interviews and observation. Detailed field notes from the interview and observation sessions were used as the primary data source for the study. Qualitative interview is an appropriate and useful method for investigating questions related to healthcare (Britten, 1995) and has been used periodically in aphasia research (see e.g., Hersh, 2015; Le Dorze, Salois-Bellerose, Alepins, Croteau, \& Hallé, 2014).

Interviews involving participants with aphasia were completed at either the participant's home or at a central meeting location for an aphasia program. All participants were given the option of being interviewed alone or with a family member. Four had a family member present during the interview (see Table 1). SLPs, on the other hand, were mostly interviewed by phone with only one being interviewed in person. Consistent with semi-structured interview methodology, the order and wording of questions were not identical during each interview, 
which allowed some flexibility during the interview process (Britten, 1995; Halcomb \& Davidson, 2006).

One way in which interviews were modified depending on the needs of individual participants was through the use of supported communication strategies to ensure comprehension and verify responses. These strategies were especially critical when interviewing participants with severe aphasia (i.e., PWA1, PWA2, PWA3). To support comprehension, interviewers drew from techniques presented by Kagan (1998) such as using simple sentences, gestures, pictures and props, written key words, and drawing as indicated. To elicit and verify responses, interviewers utilized a combination of questions, visual rating scales, and written choices. For those with severe aphasia, their input was used in conjunction with significant caregiver guidance about previous experiences. For example, a caregiver would be asked to list the various treatment or practice procedures in which the participant with aphasia participated throughout their speech therapy. The participant could then express their preferences regarding each procedure via rating scales, yes/no questions, and/or fixed choice questions. Interviewers took great care to verify responses from participants with aphasia. Such methods have been shown to be effective in obtaining valuable qualitative interview data from PWAs (Luck \& Rose, 2007).

With the exception of one, all interviews with participants with aphasia were attended by at least two investigators. One investigator asked the interview questions, guided the discussion, and demonstrated the practice techniques while another investigator, and occasionally a third observer, took detailed field notes. After each session, field notes were always reviewed by the interviewer and supplemented as needed. When multiple investigators took field notes at a single session they were cross-checked and synthesized. 
Interviews with PWAs. The interviews included two parts. First, a series of questions were used to guide an interview about previous experiences (see Supplemental Interview Guide). Interviewees were asked to comment about previous intervention related to sound production accuracy. The questions explored methods, strategies, techniques, targets, cues, responsibilities, and frequency of practice.

The second phase was a demonstration of practice techniques being considered for a new treatment that is currently in development. Demonstration of the techniques was immediately followed by questions eliciting participant feedback about the experience. We henceforth refer to this second phase of the interview as the simulated practice experience. The experience began with the participant identifying a topic he/she enjoyed talking about. Next, the interviewer began inquiring about the topic until a potential word or phrase occurred that would benefit from practice. The participant was asked to find an object or picture that would serve as a reminder of the word or phrase. The interviewer then helped the participant use a tablet computer to take photographs of these items and open them in an electronic photo album application. The interviewer introduced the idea of recording cues for practicing the target word or phrase. Access to video-recording, audio-recording, photography, and typing were all available within the photo album application. The participant was asked to audio- or video-record their family member or the clinician producing the target as a model, then shown how to move these recordings, add new ones, and delete ones they did not want.

Cues were demonstrated and varied with each participant, depending on the target they had selected and the severity of their speech production difficulties. Examples included writing part of the target, saying the beginning of the phrase, saying the target slowly, using semantic or personalized elaboration, and showing the face or mouth during production at various speeds. 
During the simulated practice, participants were encouraged to take over the recording and playback functions as soon as possible. Together, the participant with aphasia and interviewer created two to four pages in the photo album, each addressing a different target. The participant was then asked to practice saying the targets using any of the cues he or she wanted. When the participant produced the target, or part of the target, successfully, these productions were audioor video-recorded so they might serve as new practice cues. The interviewer(s) coached the participants with aphasia to help them make decisions and manage their own practice throughout the simulated practice experience. After the simulated practice, participants were asked to comment about their experience.

Interviews with SLPs. One of the three authors conducted semi-structured interviews with SLPs, following the same basic format as interviews with PWAs except rather than simulating the practice experience, the interviewer described practice techniques and how they might be applied in the context of an intervention program. General feedback about the described practice experience was elicited as well as questions about whether it was practical and whether clinicians could see themselves using it.

\section{Analysis}

The field notes were coded qualitatively using thematic analysis (Braun \& Clarke, 2006). Analysis followed a six-step, iterative process. First, the first and second authors familiarized themselves with the data by reading through the entire dataset. While both authors had been involved in data collection, this was an important first step as it allowed them to think critically about the combined set of field notes. Next, the first author studied the field notes, identified codes, and drafted a codebook. Based on these initial codes, the first and second authors used the codebook to code the entire set of field notes independently. During this process, they took notes 
regarding missing, ambiguous, or unneeded codes. Next, the coders met to review their coding, discuss discrepancies and refine the codebook. The refined codebook was then used to recode the entire set of field notes. The few discrepancies that persisted between the two coders were discussed by comparing any codes that were in disagreement to the codebook definitions and establishing consensus about which of the listed codes was most applicable. The final step was to categorize the codes by theme. Again, this was done in collaboration between the first and second authors. The themes, codes, and their description are outlined in Table 3.

[Table 3 near here]

\section{Results}

Four overlapping themes were apparent. Three ("experience with treatment," "experience with practice," and "therapeutic engagement") related to participants' previous experiences receiving or administering speech production treatment. The final theme ("procedural choicemaking") related to the simulated practice experience. Two codes, which were shared between PWAs and SLPs (treatment methods and treatment targets) were categorized under the “experience with treatment" theme. Four codes, shared between PWAs and SLPs (practice methods, practice cues, practice intensity, and barriers to practice) were categorized under the “experience with practice" theme. One code that overlapped for participants with aphasia and SLPs (motivation), one code that was present only for the participants with aphasia (preferences) and one code that was evident only for the SLPs (keys to successful practice) were included in the theme "therapeutic engagement." Table 4 summarizes and synthesizes the responses from both groups.

[Table 4 near here]

\section{Experience with Treatment}


Treatment Methods. PWAs and SLPs described using a variety of methods to treat speech production in therapy. Specifically, participants with aphasia identified confrontation naming, repetition practice, phoneme production practice, and script training as methods used during previous speech therapy. Two participants with aphasia mentioned methods that involved visual feedback (i.e., using a mirror and speech entrainment). Conversation groups were also mentioned by two participants with aphasia as a treatment method. SLPs indicated that they often used an eclectic approach when treating speech production in aphasia and that the methods they use vary depending on the patient and his or her progress. Four of the seven SLPs commented about their use of graded tasks (i.e., gradually increasing task complexity during treatment). Specific methods identified by SLPs included confrontation naming, script training, melodic intonation therapy, response elaboration training, and general articulation training. Two SLPs mentioned conducting therapy tasks in the context of conversation and two commented on their use of technology during therapy when treating speech production in aphasia.

Treatment Targets. PWAs reported that targets were mostly selected by the therapist and said that they wanted to be more involved in the decision-making. A number of PWAs expressed particular dissatisfaction with their lack of involvement in identifying treatment targets. For example, PWA2 described coming to the realization that, "I'm not going to use these type of words," and PWA3 responded that she didn't feel like she used the targeted words and phrases in her life. While this was the overall sentiment of the group, PWA3 also responded that she collaborated with an SLP on developing "some" targets. In contrast to PWAs, most SLPs described target selection as a collaborative process although they admitted that "sometimes it's hard to get [PWAs] to tell you what they want to [target in therapy]." All SLPs commented on the importance of "functional" targets that are related to the specific interests of PWAs. Several 
SLPs described using photos and technology to develop personalized targets. Two SLPs mentioned using workbooks and picture cue cards "only as a last resort."

\section{Experience with Practice}

Practice Methods. PWAs mostly discussed using drill-based practice to improve speech production outside of therapy; however, conversation-based practice was also mentioned. Drillbased practice methods that PWAs mentioned included repeating words, phrases, and scripts, reading out loud, and practice producing specific sounds. PWAs also identified speech strategies that they had practiced in conjunction with previous treatment. These strategies included reducing speech rate, separating out syllables, writing out initial letters, and taping up papers around the house with words and phrases to practice. Three PWAs discussed everyday conversations as part of their practice routine. For example, PWA6 described going to stores and restaurants to be able to practice talking as much as possible and PWA5 said that interaction with friends and family was an important practice method. Similar to participants with aphasia, SLPs mentioned assigning drill practice for specific target items and "carryover assignments" for bringing what was practiced into an everyday communicative context. The most common practice method that SLPs commented on involved drilling lists of words or phrases that were sent home. Some SLPs described recording their own productions of these lists so that their clients could practice with their model while others explained relying on others (e.g., caregivers, PTs, OTs) for assistance with practice. Four SLPs reported assigning practice in naturalistic contexts. For example, SLP5 stated that she asked clients with aphasia to practice functional phrases in the "actual situation that they are intended for," and SLP1 commented on asking clients to practice their speech "while exercising" and "with different conversation partners." 
Practice Cues. Both participants with aphasia and SLPs reported using a variety of cues to practice speech production. PWAs identified practice cues such as writing the target word on paper, visualizing the target word in their mind, choral speech, and repetition following a model from their caregiver. Four specifically mentioned using written cues and two (PWA3 and PWA6) suggested that these were preferred over other cueing strategies. PWA2 commented about the importance of "different cues" such as seeing the word, hearing the word, and reading the word. SLPs also mentioned a variety of practice cues including visual cues such as pictured items and written words, and auditory cues such as phonemic prompts and repetition. They also identified syllable segmentation, rhythm/tapping, and descriptions of articulatory placement as helpful cueing strategies. Three SLPs mentioned the importance of using a cueing hierarchy.

Practice Intensity. There was a broad range in how much participants with aphasia reported practicing. Four of them said that they practiced daily; however, the amount of daily speech practice ranged from "a little bit" to approximately two hours per day. Others said they only practiced "sometimes" or "not as much as I should." PWA6 indicated that he "started doing a little more at home" once the targets were something he "enjoyed." SLPs suggested that, while the amount of practice varies by individual, it is often much less than what is assigned. For example, SLP2 suggested that clients typically only practice about $30 \%$ of the time they are asked to practice.

Barriers to Practice. The most common barriers to practice that our participants with aphasia addressed were frustration and lack of motivation. PWA6 described the frustration that accompanies speech practice by explaining how quickly he learned words as a school-aged child, then stating that now he can practice words repeatedly and still have difficulty. The lack of motivation to practice described by participants with aphasia was most often tied to a sentiment 
that what they were doing was ineffective. For example, after the interviewers discovered that she used to practice at home but rarely does anymore, PWA1 expressed that she could have continued to practice but didn't because it was "not working." PWA4 simply stated that she does not like practicing. Two participants with aphasia indicated that practicing alone (i.e., without support from others) contributed to this lack of motivation. A "lack of support" was the primary barrier to practice identified by SLPs. SLP2 said, "when caregivers are not supportive, patients stop practicing." SLP1 echoed this sentiment by stating, "you have to rely on the family [to help carry through with practice]." SLPs also mentioned "depression," "frustration," "lack of motivation," limited interests, and lack of time as barriers to practice.

\section{Therapeutic Engagement}

Motivation. Participants with aphasia and SLPs discussed factors that increased motivation from the perspective of those receiving and administering therapy. Those with aphasia commented that their motivation resulted from targets that were interesting and meaningful, a desire to improve, and a belief that they would improve. For example, when asked about reasons for practicing PWA7 sat straight up in her chair and said, "I want to speak better!" and PWA1 indicated that she thought maybe it would "work." Multiple SLPs commented that personally relevant targets, tangible life goals, and involved families help to motivate their clients. They also mentioned helping PWAs see their progress and making them accountable. Unfortunately, several participants with aphasia reported low levels of personal motivation.

Preferences. Two participants with aphasia expressed clear preferences related to previous therapy and practice techniques. They commented that they would prefer to incorporate practice into conversations or daily tasks. PWA2 stated that, to him, the most important thing in practice was to be given "options of what to do." 
Keys to Successful Speech Practice. The keys to successful speech practice that SLPs identified were very much in line with what they perceived as being motivating to their clients. Three SLPs suggested that client-driven therapy and practice are keys to success. For example, SLP3 indicated that "making them a partner by asking them what they want to do" was critical. Two SLPs discussed the importance of repetition to successful speech practice. Others mentioned flexibility, using "a variety of media to present cues," "practice in challenging settings," and "at least one good support person" as keys to successful speech practice.

\section{Procedural Choice-Making}

The "procedural choice-making" theme was identified based on observation and feedback during the simulated practice experience. Three codes were captured under this theme. One code (control) was shared between the two groups and two (feasibility of implementation and cue use and preference) were specific to PWAs.

Control. Participants with aphasia indicated that a major advantage of the simulated practice experience was the opportunity to choose their own targets and the practice flexibility that it offered. Similarly, SLPs liked that the procedures described were client-driven, flexible, and focused on meaningful targets that clients choose. After the investigators described the simulated practice experience and asked for feedback, SLP2 said, "I think the more patientdriven it is the more practice you will get!" SLP3 counseled regarding the importance of keeping practice dynamic and changeable in order to maintain control and motivation over time.

Feasibility of Implementation. Observation of participants with aphasia during the simulated practice experience revealed that all were able to use the tablet application to build targets and create cues when given moderate to minimum assistance from investigators. By the end of the observation session, two of them were able to navigate the application independently 
and use for practice and cueing, while the others still needed some level of assistance. Learning to use the application also seemed feasible for those with limited prior experience mobile technology. For example, over the course of approximately 30 minutes, PWA5 learned how to record audio, take pictures, and self-cue with the application despite not owning a personal mobile device. Their comfort using the device is well represented by PWA4 who, when asked what she thought after piloting the tablet and application for treatment, replied, "good; easy!" Despite having demonstrated ability to use the device and application, some participants and caregivers were apprehensive about learning something new and thought they would need a lot of help.

Cue Use and Preference. All participants with aphasia created their own cues during the simulated practice experience and many demonstrated cue preferences. Those who had less severe aphasia gravitated toward auditory and/or written cues. All four participants with moderate or mild aphasia demonstrated improved productions with auditory cues and both PWA4 and PWA6 specifically improved their multisyllabic word production following auditory cues that were segmented by syllable. Three participants chose to use written cues (through a video of the investigator writing the target word) and the two with APP commented on the usefulness of these cues. For example, PWA6 felt that a written cue helped him to slow down and process the words and syllables. Participants with severe aphasia also used auditory cues but required more support from the interviewer to do so effectively. PWA1 preferred using pictures to remind her of what to say. Most reacted with positive facial expressions after hearing their own production of a target and several asked to hear it again. After hearing her own recording of a single-word production, PWA4 smiled and said, "I love it!"

\section{Discussion}


The purpose of the present study was to uncover principles that drive successful speech production treatment and practice by evaluating the social validity of (1) previously experienced goals and procedures and (2) choice-making techniques for client-driven training of speech production in aphasia. Results indicated that consumers valued personally relevant goals and targets as well as choice and flexibility during practice. We also found that participants in both groups had experienced a diverse array of treatment, practice, and cueing methods and that some PWAs lack motivation and fail to practice as much as they believe they should. Finally, we found through a simulated practice experience that applying principles of self-management and procedural choice-making to train speech production was feasible and might increase perceived control. Apprehension about using new technology was also noted.

\section{Past Experiences and Potential Strategies}

The reason for asking PWAs and SLPs about the importance and acceptability of treatment goals and procedures they had experienced previously was to inform the design of speech production interventions we are currently developing so implementation would be feasible. The results identified important features for enhancing social validity at both levels.

Socially valid goals. Personally relevant targets were identified by both groups as being key to the engagement in treatment tasks under the motivation code. Interestingly, the groups had differing perceptions about who typically selected target items. Perhaps one of the reasons for this discrepancy was the difficulty that SLPs expressed with getting their clients to tell them what they wanted to work on in therapy. Another possibility is that differing perceptions were found because the PWAs we interviewed were not necessarily treated by the SLPs we interviewed. It is important to consider, however, that perceptions of any given intervention can differ markedly between clinicians who strive to implement client-centered practice and 
participating stroke survivors (Maitra \& Erway, 2006). Assuming the reality of different perspectives, one solution would be for SLPs and PWAs to collaboratively identify personally relevant targets prior to treatment, using practical frameworks for detailing how intervention might address those goals (e.g., Haley, Richardson, Jacks, \& de Riesthal, 2015; Haley, Womack, Helm-Estabrooks, Lovette, \& Goff, 2013; Hersh et al., 2012). For more short-term planning, SLPs might draw upon techniques common to script training to identify conversation topics of interest. These include a discussion of personal interests and common communication partners, a review of examples that have been used successfully by others, and a demonstration of what target words and phrases might look like for potentially relevant topics (Goldberg et al., 2012; Holland et al., 2010). Once personally meaningful topics have been discussed, specific targets related to the topic are ideally also identified collaboratively. The simulated practice experience in the present study began with piloting iterative and informal methods for collaborative goal selection.

A more general goal that PWAs often have is to recover their communication abilities (Worrall et al., 2011). Findings from the present study confirmed that in their previous speech production treatment experience, perceived progress played an important role in motivating PWAs to engage fully in speech rehabilitation. Unfortunately, this goal was not always met as several participants with aphasia did not perceive that practice outside of therapy sessions was effective. While finding ways to help PWAs improve is crucial, helping them recognize the improvements they make is also important. Social validation of goals and effects may serve the dual functions of clarifying the improvement in practical terms and at the same time encouraging SLPs to address transfer to the communicative settings their clients consider important. In 
addition, applying socially valid treatment procedures is likely to aid PWAs in recognizing their progress.

Socially valid procedures. Both groups reported experiences with a large array of approaches, home practice techniques, and cueing strategies during previous treatment. Interviews suggested that one reason for this assortment of approaches and techniques was that SLPs change their treatment approach based on individual patients and how they progress throughout therapy. Consequently, SLPs often draw upon a variety of principles and techniques from therapy programs rather than adhering to a specific program. The tendency for SLPs to modify therapy programs based on client's needs is in line with the implementation science literature, which suggests that the degree to which interventions can be adapted to meet local needs plays in important role in the success of implementation (Damschroder et al., 2009). The importance of adaptability is further supported by the finding from our study that certain practice techniques and cueing strategies (e.g., practicing speech by talking to people in stores, using written cues) were more strongly preferred by some participants than others.

Practice in naturalistic contexts and procedures that facilitate choice appear to be valued components of speech production intervention. Although drill-based practice was the most common method reported for practicing outside of therapy, both groups expressed that practice in more natural contexts was important (e.g., functional activities, conversation with friends and family, vocabulary related to profession). Participants with aphasia preferred incorporating practice into their daily interactions and both groups thought that choice and flexibility were important in speech practice.

Participants' comments regarding motivation and practice intensity are likely related to treatment and practice procedures. Findings from our interviews suggested that PWAs often 
struggle to stay motivated and rarely practice as much as they, their therapists, or the literature suggest they should. It is probable that treatment goals and procedures influence motivation as well as practice intensity and that greater client input would have positive effects on these outcomes. This expectation is consistent with self-determination theory, which posits that when people's need for autonomy is satisfied, they are more likely to exert effort and persist in pursuing behavioral goals (Deci \& Ryan, 1987).

Summary of interview results. Our findings regarding previously experienced speech production interventions have the potential to help us develop more robust treatments. First, understanding that PWAs often want to play a more active role in determining goals and targets helps justify prioritization of collaborative goal selection. Second, based on comments from participants with aphasia indicating that practice did not always seem effective and the perception of participants from both groups that seeing progress during treatment increases motivation, treatments should pursue effective strategies to help PWAs recognize their progress. Third, knowing that most PWAs and SLPs are familiar with a variety of approaches, techniques, and strategies related to speech production treatment indicates that they are not tied to one specific approach or program and may be willing to adopt strategies that afford customization and flexibility. Fourth, PWAs and SLPs seem to favor practice that involves choice, flexibility, and real communication. Fifth, some PWAs lack motivation and practice little; these are likely to benefit from self-endorsement of goals and procedures.

\section{Input about the Simulated Practice Experience}

The purpose of the simulated practice experience was to evaluate consumer's perceptions regarding their overall experience with procedures that incorporated principles of selfmanagement and procedural choice-making, and to determine the feasibility of applying these 
procedures to treatment and practice. We hoped to learn whether a client-driven practice approach would be practical. Using a tablet computer, we collaboratively identified conversation topics, assisted study participants in creating their own speech targets and cues, and facilitated self-initiated practice and self-evaluation of target productions. These procedures were developed based on strategies that have been shown to support autonomy and competence (Bandura, 1997; Deci \& Ryan, 1987). Our finding that both PWAs and SLPs valued the choice of targets and flexibility during practice indicated feasibility of entrusting control of key practice variables to PWAs. Feasibility of implementation was further indicated by the observation that all PWAs learned and used the device to create and practice their own target stimuli and production cues.

Control and autonomy support. Both participants with aphasia and SLPs indicated that a strength of the simulated/described practice experience was that it facilitated choice. Additionally, despite the short duration of the simulated practice session, many participants with aphasia demonstrated individual preferences, especially in relation to cues. The practice allowed them to develop their own cues for each target item and choose what cues they used during practice. Previous studies have investigated using cues that PWAs develop (Freed et al., 2004), exposing PWAs to multiple cueing options (Doesborgh et al., 2004; Ramsberger \& Marie, 2007), and letting PWAs choose between audio and audiovisual cues during treatment (de Riesthal, Steele, \& Ball, 2016). There is some evidence that these treatment approaches lead to improved naming (Doesborgh et al., 2004; Freed et al., 2004). Procedural choice-making during the simulated practice experience combined previously used strategies by helping participants develop audio, video, written, and other cues and then use those cues during practice. Results indicated that these options were well received and appreciated. Interestingly, there was some 
indication that PWAs preferred cues that would be expected to be most useful given their speech production deficits (e.g., the two with APP perceived written cues as most useful whereas those with AOS preferred video or audio recorded cues).

Procedures that support competence. Throughout the simulated practice, several participants benefited from and preferred auditory cues that were broken down into syllabic segments. Graded tasks are integral to many treatment paradigms (see e.g., Albert et al., 1973; Kearns, 1985; Wambaugh et al., 1998) and support competence by ensuring a comfortable or manageable level of difficulty at different stages of learning and skill acquisition. PWAs also reacted positively after hearing a recording of their own production of the target and subsequently used these self-recordings to cue themselves during the simulated practice session. Self-modeling is a method that has been used to improve behavior in a variety of populations by exposing people to their own positive or accurate behaviors and, thus, increasing their selfefficacy (Dowrick, 1999). It has been applied to treatment in communication disorders and shown to improve speech production in people who stutter and help them better maintain treatment gains (Bray \& Kehle, 1998; Cream, O’Brian, Onslow, Packman, \& Menzies, 2009). Our results indicate that competence-supportive procedures, such as graded tasks and selfmodeling were valued. Future research will need to formulate how to establish appropriate balance between practice complexity and practice autonomy.

Technological Apprehension. The use of mobile technology in aphasia therapy is becoming more common and an increasing number of older adults own mobile technology devices (e.g., Brandenburg, Worrall, Copland, Power, \& Rodriguez, 2015; Des Roches, Balachandran, Ascenso, Tripodis, \& Kiran, 2014; Stark \& Warburton, 2016). Yet, we learned from the present study that even when participants with aphasia demonstrated appropriate use of 
the device and seemed comfortable with the technology, they were not always confident in their ability to learn to use the device independently. Incorporating technology training into the treatment program is likely to help users overcome this apprehension about technology (see Szabo \& Dittelman, 2014). In addition, as participants with aphasia experience successful use of technology their confidence is likely to increase (Bandura, 1997). Before integrating technology into a therapy program vision, motor skills, and cognitive functioning should all be considered.

\section{Proactive Use of Social Validation Results}

We have discussed aspects of a simulated practice experience for speech production treatment designed to increase motivation by supporting autonomy and competence. We anticipate further that the act of socially validating treatment goals and procedures prior to testing their outcomes will improve implementation of these treatments in clinical settings. Since its introduction to behavioral sciences, involving consumers from the beginning of treatment development has been the intent of social validation methods (Wolf, 1978). We suspect that involving PWAs and SLPs from the earliest stages of treatment development will benefit stakeholders and researchers alike.

These suspected mutual benefits fit nicely within the context of implementation science. In a recent article applying principles from implementation science to communication sciences and disorders, Douglas, Campbell, and Hinckley (2015) suggested that researchers could frame their studies from an implementation science perspective by "engag[ing] all stakeholders in the research process" (Douglas et al., 2015, p. S1830). They argue that involving clinicians who deliver interventions, clients who receive treatment, and other community members, can help with the implementation of evidence-based practice. As such, implementation science offers a complementary perspective on the social validation objectives we applied to the present study. 


\section{Conclusions}

Because the present study only included seven participants with aphasia and eight SLPs, a larger study is needed to confirm the results. In addition, the simulated treatment experience was limited to one or two sessions with PWAs and a description/explanation with SLPs. Nevertheless, preliminary conclusions can be derived to help us move forward in our development of speech production intervention principles that are important and acceptable to consumers (i.e., socially valid). Our social validation confirmed the motivational value of clientselected treatment targets and procedures and identified key factors for implementation planning. We found that PWAs value treatment goals and procedures that are likely to increase personal motivation such as offering them choice and helping them recognize progress. This is important in training speech production because, based on our qualitative findings, the home practice rate or intensity may be insufficient.

Our findings also revealed factors likely to support successful implementation of speech production training in aphasia. First, SLPs — who already use an eclectic approach and variety of cues_-value choice about treatment targets and procedures. For this reason, we anticipate that SLPs will prefer treatments that are flexible and adaptable to them and their client's needs. Second, the discrepancy between PWAs and SLPs about who typically selects treatment targets suggests that clinicians will appreciate strategies for supporting their collaboration with people who have aphasia. Third, training and familiarization with technology may be needed to reduce apprehension about using technology independently. All three strategies may be important components for effective implementation. Finally, based on our simulated practice experience, a self-directed treatment approach that incorporates procedural choice-making throughout the training process appears feasible. We anticipate that careful planning of the staged learning 
experience will be critical as we draw from these findings to develop and evaluate a complete treatment protocol experimentally. 


\section{References}

Albert, M. L., Sparks, R. W., \& Helm, N. A. (1973). Melodic intonation therapy for aphasia. Archives of Neurology, 2130, 4-5.

Ballard, K. J., Wambaugh, J. L., Duffy, J. R., Layfield, C., Maas, E., Mauszycki, S. C., \& McNeil, M. R. (2015). Treatment for acquired apraxia of speech: A systematic review of intervention research between 2004 and 2012. Journal of Speech, Language, and Hearing Research, 24(May 2015), 316-337. http://doi.org/10.1044/2015

Bandura, A. (1997). Self-efficacy: The exercise of control. New York: W. H. Freeman and Company.

Bhogal, S. K., Teasell, R. W., Foley, N. C., \& Speechley, M. R. (2003). Rehabilitation of aphasia: More is better. Topics in Stroke Rehabilitation, 10(2), 66-76.

Biel, M., Nitta, L., \& Jackson, C. (2017). Understanding Motivation in Aphasia Rehabilitation. In Aphasia Rehabilitation: Clinical Challenges (pp. 393-436).

Brandenburg, C., Worrall, L., Copland, D., Power, E., \& Rodriguez, A. D. (2015). The development and accuracy testing of $\mathrm{CommFit}^{\mathrm{TM}}$, an iPhone application for individuals with aphasia. Aphasiology, (August), 1-19. http://doi.org/10.1080/02687038.2015.1028329

Braun, V., \& Clarke, V. (2006). Using thematic analysis in psychology. Qualitative Research in Psychology, 3(2), 77-101. http://doi.org/10.1191/1478088706qp063oa

Bray, M. A., \& Kehle, T. J. (1998). Self-modeling as an intervention for stuttering. School Psychology Review, 27(4), 587-598.

Brendel, B., \& Ziegler, W. (2008). Effectiveness of metrical pacing in the treatment of apraxia of speech. Aphasiology, 22(1), 77-102. http://doi.org/10.1080/02687030600965464 
Britten, N. (1995). Qualitative interviews in medical research. BMJ (Clinical Research Ed.), 311(6999), 251-253. http://doi.org/10.1136/bmj.311.6999.251

Cherney, L. R. (2012). Aphasia treatment: intensity, dose parameters, and script training. International Journal of Speech-Language Pathology, 14(5), 424-31. http://doi.org/10.3109/17549507.2012.686629

Cream, A., O’Brian, S., Onslow, M., Packman, A., \& Menzies, R. (2009). Self-modelling as a relapse intervention following speech-restructuring treatment for stuttering. International Journal of Language \& Communication Disorders, 44(5), 587-99. http://doi.org/10.1080/13682820802256973

Damschroder, L. J., Aron, D. C., Keith, R. E., Kirsh, S. R., Alexander, J. a, \& Lowery, J. C. (2009). Fostering implementation of health services research findings into practice: a consolidated framework for advancing implementation science. Implementation Science, 4(50), 40-55. http://doi.org/10.1186/1748-5908-4-50

de Riesthal, M., Steele, R., \& Ball, A. (2016). Practice behaviors of persons with aphasia on computer-based word production tasks. Poster presented at the Clinical Aphasiology Conference, Charlottesville, VA.

Deci, E. L., \& Ryan, R. M. (1987). The support of autonomy and the control of behavior. Journal of Personality and Social Psychology, 53(6), 1024-1037. http://doi.org/10.1037/0022-3514.53.6.1024

Deci, E. L., \& Ryan, R. M. (2012). Motivation, personality, and development within embedded social contexts: An overview of self-determination theory. In R. M. Ryan (Ed.), The Oxford Handbook of Human Motivation.

http://doi.org/10.1093/oxfordhb/9780195399820.013.0006 
Des Roches, C. A., Balachandran, I., Ascenso, E. M., Tripodis, Y., \& Kiran, S. (2014).

Effectiveness of an impairment-based individualized rehabilitation program using an iPadbased software platform. Frontiers in Human Neuroscience, 8(JAN), 1015. http://doi.org/10.3389/fnhum.2014.01015

Doesborgh, S., van de Sandt-Koenderman, M., Dippel, D., van Harskamp, F., Koudstaal, P., \& Visch-Brink, E. (2004). Cues on request: The efficacy of Multicue, a computer program for wordfinding therapy. Aphasiology, 18(3), 213-222.

http://doi.org/10.1080/02687030344000580

Douglas, N. F., Campbell, W. N., \& Hinckley, J. J. (2015). Implementation science: Buzzword or game changer? Journal of Speech, Language, and Hearing Research, 58(December), S1827-S1836. http://doi.org/10.1044/2015

Dowrick, P. W. (1999). A review of self modeling and related interventions. Applied and Preventive Psychology, 8, 23-39. http://doi.org/10.1016/S0962-1849(99)80009-2

Franklin, S., Buerk, F., \& Howard, D. (2002). Generalised improvement in speech production for a subject with reproduction conduction aphasia. Aphasiology, 16(10-11), 1087-1114. http://doi.org/10.1080/02687030244000491

Freed, D., Celery, K., \& Marshall, R. (2004). Effectiveness of personalised and phonological cueing on long-term naming performance by aphasic subjects: A clinical investigation. Aphasiology, 18(8), 743-757. http://doi.org/10.1080/02687030444000246

Goldberg, S., Haley, K. L., \& Jacks, A. (2012). Script Training and Generalization for People With Aphasia. American Journal of Speech-Language Pathology, 21(August), 222-239. http://doi.org/10.1044/1058-0360(2012/11-0056)

Halcomb, E. J., \& Davidson, P. M. (2006). Is verbatim transcription of interview data always 
necessary? Applied Nursing Research, 19(1), 38-42.

http://doi.org/10.1016/j.apnr.2005.06.001

Haley, K. L., Jacks, A., de Riesthal, M., Abou-Khalil, R., \& Roth, H. L. (2012). Toward a quantitative basis for assessment and diagnosis of apraxia of speech. Journal of Speech, Language, and Hearing Research, 55(October 2012), 1502-1517.

Haley, K. L., Richardson, J. D., Jacks, A., \& de Riesthal, M. (2015). Setting goals for communicative life participation in aphasia. Abstract presented at the Annual Convention of the American Speech-Language-Hearing Association, Denver, CO.

Haley, K. L., Womack, J., Helm-Estabrooks, N., Lovette, B., \& Goff, R. (2013). Supporting autonomy for people with aphasia: use of the Life Interests and Values (LIV) Cards. Topics in Stroke Rehabilitation, 20(1), 22-35. http://doi.org/10.1310/tsr2001-22

Hersh, D. (2015). “Hopeless, sorry, hopeless.” Topics in Language Disorders, 35(3), 219-236. http://doi.org/10.1097/TLD.0000000000000060

Hersh, D., Worrall, L., Howe, T., Sherratt, S., \& Davidson, B. (2012). SMARTER goal setting in aphasia rehabilitation. Aphasiology, 26(2), 220-233.

http://doi.org/10.1080/02687038.2011.640392

Holland, A. L., Halper, A. S., \& Cherney, L. R. (2010). Tell me your story: Analysis of script topics selected by persons with aphasia. American Journal of Speech-Language Pathology, 19(3), 198-203. http://doi.org/10.1044/1058-0360(2010/09-0095)

Kagan, A. (1998). Supported conversation for adults with aphasia: Methods and resources for training conversation partners. Aphasiology, 12(9), 816-830.

Kearns, K. (1985). Response elaboration training for patient initiated utterances. In Clinical Aphasiology Conference, 196-204. 
Kendall, D. L., Rodriguez, A. D., Rosenbek, J. C., Conway, T., \& Gonzalez-Rothi, L. J. (2006). Influence of intensive phonomotor rehabilitation on apraxia of speech. Journal of Rehabilitation Research and Development, 43(3), 409-418. http://doi.org/10.1682/JRRD.2005.11.0175

Kertesz, A. (2006). Western Aphasia Battery-Revised (WAB-R). standardized assessment, San Antonio, TX: Pearson.

Kohn, S. E., Smith, K. L., \& Arsenault, J. K. (1990). The remediation of conduction aphasia via sentence repetition: A case study. British Journal of Disorders of Communication, 25(1), 45-60. http://doi.org/10.3109/13682829009011962

Le Dorze, G., Salois-Bellerose, É., Alepins, M., Croteau, C., \& Hallé, M.-C. (2014). A description of the personal and environmental determinants of participation several years post-stroke according to the views of people who have aphasia. Aphasiology, 28(4), 421439. http://doi.org/10.1080/02687038.2013.869305

Locke, E. A., \& Latham, G. P. (2002). Building a practically useful theory of goal setting and task motivation: A 35-year odyssey. The American Psychologist, 57(9), 705-717. http://doi.org/10.1037/0003-066X.57.9.705

Luck, A. M., \& Rose, M. L. (2007). Interviewing people with aphasia: Insights into method adjustments from a pilot study. Aphasiology, 21(2), 208-224. http://doi.org/10.1080/02687030601065470

Maitra, K. K., \& Erway, F. (2006). Perception of Client-Centered Practice in Occupational Therapists and Their Clients. American Journal of Occupational Therapy, 60(3), 298-310. http://doi.org/10.5014/ajot.60.3.298

Marshall, R. C., \& Freed, D. B. (2006). The personalized cueing method: From the laboratory to 
the clinic. American Journal of Speech-Language Pathology, 15(2), 103-111. http://doi.org/10.1044/1058-0360(2006/011)

Mendel, P., Meredith, L. S., Schoenbaum, M., Sherbourne, C. D., \& Wells, K. B. (2008). Interventions in organizational and community context : A framework for building evidence on dissemination and implementation in health services research. Administration and Policy in Mental Health and Mental Health Services Research, 35(1-2), 21-37. http://doi.org/10.1007/s10488-007-0144-9

Ramsberger, G., \& Marie, B. (2007). Self-administered cued naming therapy: a singleparticipant investigation of a computer-based therapy program replicated in four cases. American Journal of Speech-Language Pathology / American Speech-Language-Hearing Association, 16(4), 343-58. http://doi.org/10.1044/1058-0360(2007/038)

Ryan, R. M., \& Deci, E. L. (2000). Intrinsic and extrinsic motivations: Classic definitions and new directions. Contemporary Educational Psychology, 25(1), 54-67. http://doi.org/10.1006/ceps.1999.1020

Rycroft-Malone, J. (2004). The PARIHS Framework-A framework for guiding the implementation of evidence-based practice. Journal of Nursing Care Quality, 19(4), 297304. http://doi.org/10.1097/00001786-200410000-00002

Schwartz, I. S., \& Baer, D. M. (1991). Social validity assessments: Is current practice state of the art? Journal of Applied Behavior Analysis, 24(2), 189-204. http://doi.org/10.1901/jaba.1991.24-189

Stark, B. C., \& Warburton, E. A. (2016). Improved language in chronic aphasia after selfdelivered iPad speech therapy. Neuropsychological Rehabilitation, 2011(March), 1-14. http://doi.org/10.1080/09602011.2016.1146150 
Szabo, G., \& Dittelman, J. (2014). Using mobile technology with individuals with aphasia : Native iPad features and everyday apps. Seminars in Speech and Language, 1(212), 5-16.

Varley, R., Cowell, P. E., Dyson, L., Inglis, L., Roper, A., \& Whiteside, S. P. (2016). Selfadministered computer therapy for apraxia of speech: Two-period randomized control trial with crossover. Stroke, 47(3), 822-828. http://doi.org/10.1161/STROKEAHA.115.011939

Wambaugh, J. L., Duffy, J. R., McNeil, M. R., Robin, D. A., \& Rogers, M. A. (2006). Treatment guidelines for acquired apraxia of speech: Treatment descriptions and recommendations. Journal of Medical Speech-Language Pathology, 14(2), xv-xxxii.

Wambaugh, J. L., Kalinyak-Fliszar, M. M., West, J. E., \& Doyle, P. J. (1998). Effects of Treatment for Sound Errors in Apraxia of Speech and Aphasia. Journal of Speech Language and Hearing Research, 41(4), 725-743.

Wambaugh, J. L., \& Martinez, A. L. (2000). Effects of rate and rhythm control treatment on consonant production accuracy in apraxia of speech. Aphasiology, 14(8), 851-871. http://doi.org/10.1080/026870300412232

Wambaugh, J. L., Nessler, C., Cameron, R., \& Mauszycki, S. C. (2012). Acquired apraxia of speech: The effects of repeated practice and rate/rhythm control treatments on sound production accuracy. American Journal of Speech-Language Pathology, 21(2), S5-S27. http://doi.org/10.1044/1058-0360(2011/11-0102)

Wambaugh, J. L., Wright, S., \& Nessler, C. (2012). Modified Response Elaboration Training: A systematic extension with replications. Aphasiology, 7038(March 2013), 1-33. http://doi.org/10.1080/02687038.2012.702887

Wambaugh, J. L., Wright, S., Nessler, C., \& Mauszycki, S. C. (2014). Combined Aphasia and Apraxia of Speech Treatment (CAAST): Effects of a Novel Therapy. Journal of Speech, 
Language and Hearing Research, 57(December), 2191-2207. http://doi.org/10.1044/2014

Wertz, R. T., LaPointe, L. L., \& Rosenbek, J. C. (1984). Apraxia of speech in adults: The disorder and its management. San Diego, CA: Singular.

Wolf, M. M. (1978). Social validity: the case for subjective measurement or how applied behavior analysis is finding its heart. Journal of Applied Behavior Analysis, 11(2), 203-214. http://doi.org/10.1901/jaba.1978.11-203

Worrall, L., Sherratt, S., Rogers, P., Howe, T., Hersh, D., Ferguson, A., \& Davidson, B. (2011). What people with aphasia want: Their goals according to the ICF. Aphasiology, 25(3), 309322. http://doi.org/10.1080/02687038.2010.508530

Youmans, G. L., Youmans, S. R., \& Hancock, A. B. (2011). Script training treatment for adults with apraxia of speech. American Journal of Speech-Language Pathology, 20(1), 23-37. http://doi.org/10.1044/1058-0360(2010/09-0085)

Youmans, S. R., Youmans, G. L., \& Hancock, A. B. (2011). The social validity of script training related to the treatment of apraxia of speech. Aphasiology, 25(9), 1078-1089. http://doi.org/10.1080/02687038.2011.577205 
Table 1. Demographic information for people with aphasia and caregiver participants.

\begin{tabular}{lcccccccc}
\hline $\begin{array}{l}\text { Participant } \\
\text { ID }\end{array}$ & Sex & Age & $\begin{array}{c}\text { Time } \\
\text { Post- } \\
\text { onset }\end{array}$ & AQ & Classification & $\begin{array}{c}\text { MSE } \\
\text { Accuracy } \\
(\%)\end{array}$ & $\begin{array}{c}\text { Speech } \\
\text { diagnosis }\end{array}$ & $\begin{array}{c}\text { Family } \\
\text { Member }\end{array}$ \\
\hline PWA1 & F & 67 & $15 ; 0$ & 33.9 & Broca's & 0.0 & AOS & $\begin{array}{c}\text { Sister } \\
\text { PWA2 }\end{array}$ \\
M & 55 & $1 ; 6$ & 41.1 & Broca's & - & AOS & Daughter \\
PWA3 & M & 67 & $0 ; 3$ & - & Global & - & AOS & Spouse \\
PWA4 & F & 45 & $16 ; 0$ & 53.2 & Broca's & 11.1 & AOS & None \\
PWA5 & F & 60 & $7 ; 11$ & 65.4 & Conduction & 72.2 & APP & None \\
PWA6 & M & 65 & $1 ; 9$ & 90.6 & Anomic & 85.2 & APP & None \\
PWA7 & F & 80 & $4 ; 4$ & 93.6 & Anomic & 26.9 & AOS & Spouse \\
\hline
\end{tabular}

Note. $\mathrm{AQ}=$ Western Aphasia Battery-Revised Aphasia Quotient; Family Member = family member who was present and participated in the interview; MSE Accuracy = Percent items correct on the word repetition portion of the motor speech evaluation. Age is represented in years and time post-onset of aphasia is represented in years and months (YY;MM). 
Table 2. Demographic information for speech-language pathologists.

\begin{tabular}{llrlc}
\hline Participant & Sex & Experience & Work Setting & $\begin{array}{c}\text { Frequency of Speech } \\
\text { Production Work (\%) }\end{array}$ \\
\hline SLP1 & F & 34 & Inpatient and outpatient Rehab & 30 \\
SLP2 & F & 10 & Outpatient rehab & 50 \\
SLP3 & F & 3 & Skilled nursing facility & 15 \\
SLP4 & F & 11 & Outpatient rehab & 10 \\
SLP5 & F & 10 & Outpatient rehab; Acute & 25 \\
& & & inpatient; Private practice & 10 \\
SLP6 & M & 1 & Inpatient rehab & 30 \\
SLP7 & F & 1 & Outpatient neurological Clinic & 15 \\
SLP8 & M & 2 & Outpatient rehab & \\
\hline
\end{tabular}

Note. Experience $=$ years of experience as a speech-language pathologist working with neurogenic communication disorders. Frequency of speech production work is represented as a percentage of caseload and was obtained via self-report. 
Table 3. Themes, codes, and descriptions.

\begin{tabular}{|c|c|c|}
\hline Theme & Code & Description \\
\hline \multirow{2}{*}{$\begin{array}{l}\text { Experience with } \\
\text { Treatment }\end{array}$} & Treatment methods & Mention of specific tasks used in therapy \\
\hline & Treatment targets & $\begin{array}{l}\text { Comments regarding treatment targets and } \\
\text { stimuli including how they were selected }\end{array}$ \\
\hline \multirow[t]{4}{*}{$\begin{array}{l}\text { Experience with } \\
\text { Practice }\end{array}$} & Practice methods & $\begin{array}{l}\text { Comments about how people with aphasia } \\
\text { practiced or were asked to practice outside of } \\
\text { therapy }\end{array}$ \\
\hline & Practice cues & $\begin{array}{l}\text { Mention of specific cues or strategies used in } \\
\text { practice }\end{array}$ \\
\hline & Practice intensity & $\begin{array}{l}\text { Comments about how much people with aphasia } \\
\text { practiced }\end{array}$ \\
\hline & Barriers to practice & $\begin{array}{l}\text { Mention of things that keep people with aphasia } \\
\text { from practicing }\end{array}$ \\
\hline \multirow[t]{3}{*}{$\begin{array}{l}\text { Therapeutic } \\
\text { Engagement }\end{array}$} & Motivation & $\begin{array}{l}\text { Comments about what motivates people with } \\
\text { aphasia to practice and/or keep practicing }\end{array}$ \\
\hline & Preferences & $\begin{array}{l}\text { Comments about what people with aphasia want } \\
\text { to practice }\end{array}$ \\
\hline & $\begin{array}{l}\text { Keys to successful } \\
\text { speech practice }\end{array}$ & $\begin{array}{l}\text { Thoughts and suggestions about the most } \\
\text { important components of speech practice }\end{array}$ \\
\hline \multirow[t]{3}{*}{$\begin{array}{l}\text { Procedural } \\
\text { Choice-Making }\end{array}$} & Control & $\begin{array}{l}\text { Comments about the role of personal choice, } \\
\text { control, and flexibility in the piloted/described } \\
\text { treatment }\end{array}$ \\
\hline & $\begin{array}{l}\text { Feasibility of } \\
\text { implementation }\end{array}$ & $\begin{array}{l}\text { Observations and comments regarding the ease } \\
\text { or difficulty of use and/or learning of the } \\
\text { treatment }\end{array}$ \\
\hline & $\begin{array}{l}\text { Cue use and } \\
\text { preference }\end{array}$ & $\begin{array}{l}\text { Observations about what cues were used, how } \\
\text { they used various cues, and people with aphasia } \\
\text { preference for certain cues }\end{array}$ \\
\hline
\end{tabular}


Table 4. Synthesis of participant responses within each theme (1-4). Codes are listed under their corresponding theme. Shared responses were mentioned by both participant groups. Group-specific responses were mentioned only by people with aphasia (PWA) or only Speech-language pathologists (SLP).

\section{Experience with Treatment}

a) Treatment methods

b) Treatment targets

\section{Experience with Practice}

a) Practice methods

b) Practice intensity

c) Practice cues

d) Practice barriers

Shared Responses Group-Specific Responses

- Confrontation naming

- Sound production training

- Repetition training

- Script training
- PWA: Conversation groups

- SLP: Often eclectic

- SLP: Varied based on the patient and progress

- PWA: Targets mostly selected by the therapist

- PWA: Wanted to be more involved in decision-making

- SLP: Try to make target selection collaborative

- SLP: "It's hard to get patients to tell you what they want to talk about."
- Mostly drill-based practice for specific target items

- Vario
cues
- PWA: Conversation-based practice

- SLP: "Carryover assignments" for bringing what was practiced into a real-life communicative context.

- PWA: Ranged from "a little bit" to 2-3 hours per day

- SLP: Patients often practice much less than what they are assigned
- PWA: Frustration

- PWA: Not feeling like practice is effective

- SLP: "Lack of support"

- SLP: Depression 


\section{Therapeutic Engagement}

a) Motivation

b) Preferences

c) Keys to successful practice

\section{Procedural Choice-making}

a) Control

b) Feasibility of implementation

c) Cue use and preference
- Interesting, meaningful, and relevant - PWA: Motivated by desire to improve targets increase motivation

- PWA: Motivated by belief that they would improve

- PWA: Limited choice and failure to see progress decrease motivation

- SLP: Tangible life goals yield greater PWA motivation

- SLP: Demonstrating progress improves PWA motivation

- SLP: Involved families help PWA stay motivated

- PWA: Targets that can be incorporated into daily life

- PWA: Choice of what to work on

- SLP: Making practice client driven through choice and flexibility

- SLP: Having "at least one good support person"
- Liked that there was choice of targets and flexibility for practice
- SLP: Treatment was patient-driven

- PWA: Able to build targets and create cues

- PWA: Comfortable with device

- PWA: Apprehension about learning to use mobile technology

- PWA: Created their own cues and many demonstrated cue preferences

- PWA: Liked that they could record their own voice when practicing 